American Journal of Pharmaceutical Education 2019; 83 (10) Article 7533.

\title{
COMMENTARY
}

\section{Guidance for Male Mentors to Support the Safety and Success of Female Mentees}

\author{
Lucas G. Hill, PharmD, ${ }^{a}$ S. Andrea Laguado, PharmD ${ }^{b}$ \\ a The University of Texas at Austin College of Pharmacy, Austin, Texas \\ ${ }^{\mathrm{b}}$ The University of Arizona/Banner University Medical Center South, Tucson, Arizona \\ Submitted January 26, 2019; accepted June 6, 2019; published December 2019.
}

\begin{abstract}
Women constitute the majority of students at US schools and colleges of pharmacy but make up only a minority of senior faculty members. In academic pharmacy, male mentors play an essential role in supporting the professional success of female mentees. These male mentors must recognize their role in creating safe and equitable environments for female mentees to learn and collaborate. They should respect the unique experiences and concerns of female mentees, particularly regarding sexual violence and harassment, and conduct themselves in a manner that prioritizes safety. They should also strive to develop the same interpersonal connections with female mentees that they work to develop with male mentees, realizing that maintaining inequitable personal distance from women undermines their professional success. Specific suggestions for balancing the potentially competing concepts of mentee safety and personal connection are offered by the authors, a male faculty mentor and female student mentee pair.
\end{abstract}

Keywords: mentorship, harassment, professional development, professionalism, faculty development

\section{INTRODUCTION}

In fall 2018, women accounted for $63.0 \%$ of professional students and $54.4 \%$ of full-time graduate students in US colleges and schools of pharmacy. ${ }^{1}$ Although issues that threaten the personal safety and professional success of our female students would warrant thorough consideration even if they constituted a small proportion of learners, the fact that they constitute the majority makes addressing such issues even more pressing. One in five women will be raped during her lifetime, and one in four women in college have already experienced unwanted sexual contact. ${ }^{2,3}$ More than $80 \%$ of women have experienced sexual harassment or assault in some form. ${ }^{4}$ The disproportionate sexual violence and harassment faced by women is being publicly recognized globally through the \#MeToo movement. ${ }^{4}$

A survey by LeanIn.org found evidence of a potential backlash to the \#MeToo movement as $60 \%$ of male managers reported being uncomfortable mentoring, working alone, or socializing with a woman at work. ${ }^{5}$ This finding raises concerns that male mentors in academic pharmacy may be hesitant to engage with female mentees. While women make up $50.3 \%$ of full-time pharmacy faculty members, they represent only $33.0 \%$ of full professors and $37.5 \%$ of deans and associate deans. ${ }^{6}$ The advancement and

Corresponding Author: Lucas G. Hill, The University of Texas at Austin College of Pharmacy, 2409 University Ave., Stop A1910, PHR 2.222G, Austin, TX 78712. Tel: 512-2327832. Email: lucas.hill@austin.utexas.edu professional development of future pharmacists and academicians can be powerfully influenced by a single mentor. Diminished access to male mentors could be disastrous for female students and junior faculty as a minority of experienced mentors are female.

We recognize that most male mentors in academic pharmacy strive to provide equitable support to all mentees regardless of demographic profile. However, even wellmeaning mentors can make subtle mistakes that impact female mentees negatively. We propose that two core principles can support the development of respectful and supportive mentoring relationships between members of the opposite sex: establish a safe environment, and think before speaking or touching. We reject the notion that protection of the male mentor should be the primary concern given that there is scarce evidence demonstrating any risk of false harassment or assault claims. ${ }^{7}$ Furthermore, we contend that development of a personal connection with a mentor can be extremely valuable. Members of the millennial generation, to which both authors belong, desire personal connection with mentors that extends beyond the classroom. ${ }^{8,9}$ It is through these casual interactions that strong personal bonds are formed, propelling mentees' careers forward. ${ }^{10}$

The principles outlined in this commentary are intended to support the development of safe, respectful, and beneficial relationships between male mentors and female mentees. We acknowledge that our cisgendered, 


\section{American Journal of Pharmaceutical Education 2019; 83 (10) Article 7533.}

heterosexual, interethnic, faculty mentor - student mentee perspective does not represent the full range of mentoring dynamics in academic pharmacy. However, we hope it may provide some insight for mentoring relationships in which there are complex power dynamics influenced by other gender identities, romantic preferences, or cultural backgrounds, including faculty mentor - faculty mentee relationships.

\section{Establish a Safe Environment.}

Because sexual harassment and violence are committed against men far less often than women, men can be ignorant of the dangers women face in mundane situations. For example, a male student may not be concerned about meeting in a female professor's office at 5:30 PM on Friday. However, a female student might be hesitant to meet with a male professor in a private space at a time when there might be no other personnel in the office suite or building. Male mentors bear a responsibility to consider these concerns proactively when advising female mentees.

Many factors could affect a female student's perception of safety in this situation. For this reason, we suggest gaining a female mentee's consent regarding a meeting location and time. This could be as simple as replying to a meeting request email with, "I am available to meet on Friday at 5:30 PM. Does that work for you? Let me know if you prefer a location other than my office." Compare this to, "I am available Friday at 5:30 PM in my office." Which email empowers the mentee to express a preference for an alternate time or location? If a male mentor realizes he has overlooked these concerns upon the female mentee's arrival, he should remember that it is never too late to ask for consent. He might even suggest a specific alternative to ensure the student knows the offer is genuine. For example, "It slipped my mind that everybody would be gone for the day. Would you prefer if we moved out to the courtyard?"

As a mentoring relationship progresses, male mentors and female mentees may find themselves in increasingly casual and private situations. Consider an example of a male mentor with one female and one male student mentee set to present a platform session together at a regional conference located a few hours away. The male mentor identifies it as an opportunity to develop a greater personal connection in the mentoring relationships and sends a group email offering to transport the mentees in his personal vehicle. The female mentee accepts, but the male mentee declines. If you were the male mentor in this example, how would you proceed?

Proceeding with the trip without discussing the new dynamic is discouraged, as it does not prioritize the female mentee's perception of safety. Fabricating an excuse to avoid transporting the female mentee is also suboptimal because it models dishonest, avoidant behavior that may undermine the mentoring relationship. We suggest the best answer is to give the mentee an opportunity to rescind her acceptance of the transportation offer. For example, the male mentor might say, "I was not planning to subject you to four hours alone in the car with a professor. You are still welcome to ride with me, but I would not be offended if you made different plans." Communicating this through email or another medium that gives the mentee time to consider her feelings carefully before replying is ideal. Male mentors who do not feel comfortable driving alone with the female mentee should avoid making the initial group carpool suggestion.

In addition to establishing an environment that is physically safe, a mentor should create a sense of intellectual security and empowerment that recognizes potential differences between sexes. The ultimate goal of the mentor should be to create an environment in which the female mentee feels valued, encouraged to express her views, and empowered to advocate for herself. Consider the example of a female mentee who is collaborating with a male peer and male mentor to produce a manuscript. The female student may be less assertive than a male student in a discussion of manuscript authorship based on an understanding that assertive women are often viewed more negatively than passive women by collaborators. ${ }^{11}$ In an effort to ensure appropriate credit is given to each coauthor, the supervising author should initiate a proactive discussion with all co-authors regarding their contributions and order of authorship. Regardless of the final order of authors, engaging in this exercise could allay a female mentee's concern that gender solidarity or implicit bias is driving the decision.

\section{Think Before Speaking or Touching.}

Seventy-seven percent of women experience verbal sexual harassment, which can range from unwanted comments like, "Give me a smile," to more offensive remarks referring to their bodies or sexuality directly. ${ }^{4}$ These types of sexual harassment faced by medical, nursing, and dental trainees have been documented, though similar documentation for pharmacy trainees is unavailable. ${ }^{12-14}$ In addition to comments made in the presence of female mentees, male counterparts may engage in sexualized discussion of a female mentee or colleague in private. These comments contribute to a hostile work environment for women. Male mentors must take a proactive stance to address inappropriate comments of this sort from colleagues.

Non-sexual comments regarding a person's size such as, "You are so little, I just want to put you in my pocket!" 


\section{American Journal of Pharmaceutical Education 2019; 83 (10) Article 7533.}

can also be detrimental to a female mentee and the development of trust in a mentoring relationship. ${ }^{15}$ Male mentors should generally avoid remarking on the physical appearance of female mentees and should also be mindful of the way they speak about other women in the presence of those mentees. For example, a male mentor may be discussing potential new team members for a project and dismiss a female candidate as too emotional to handle critical feedback. ${ }^{16}$ This comment could undermine the female mentee's trust in the male mentor.

Physical contact between a male mentor and female mentee is a particularly difficult issue to address in a consistent manner as personal dynamics and cultural customs can lead to substantial variation in what may be considered appropriate. To allow for more clarity, physical contact for the purpose of education should be distinguished from physical contact in a personal or emotional context. Regarding education, faculty members should observe the same decorum of asking prior to touching that is recommended when examining a patient. The request should also be accompanied by an explanation of the extent and purpose of the proposed contact. For example, we suggest a male mentor ask, "May I touch your leg to demonstrate an assessment for peripheral edema? I will only touch below the knee and will hold my fingers in place here [pointing] for a few seconds while supporting your leg from behind. This will allow me to observe whether there is any pitting characteristic consistent with excessive fluid."

We advise that male mentors should not initiate physical contact in a personal context, though there may be situations in which doing so is acceptable. Consider the case of a mentee who hopes to complete a postgraduate residency but does not match with a program. If the mentor has developed a close relationship with her, he might identify that placing a hand on her shoulder or engaging in a brief hug would be comforting. However, a substantial risk of misjudgment exists in this scenario. If the male mentor is not absolutely certain, he should either ask for consent or avoid acting on the impulse.

Inappropriate physical contact can be upsetting and isolating for female mentees. ${ }^{17}$ Both authors have observed, experienced, and heard numerous instances of such behavior. Some examples of unnecessary and inappropriate contact include prolonged touching of the mentee's arm or back while speaking; standing very close or directly against the mentee in an uncrowded space; using the mentee as an armrest and playing with her hair; and making obvious conversational excuses to touch the mentee. In one case of the latter, a male mentor told a story about another woman's necklace while tracing the outline of a necklace on a female mentee's upper chest. In addition to actual physical touch, objectifying female mentees by staring at their bodies is an unacceptable intrusion. ${ }^{18,19}$ Male mentors should not engage in any of these behaviors and we encourage them to educate colleagues who do.

\section{CONCLUSION}

Though women represent a growing proportion of mentors and most students in academic pharmacy, men still occupy most positions of leadership. Men throughout academic pharmacy have a responsibility to serve as effective mentors for female mentees. In order to do so, they should prioritize female mentee safety while pursuing personal connections that are equitable to those they engage in with male mentees. We contend this can be achieved by establishing safe physical and intellectual environments, considering the language used when communicating with or about women, and avoiding inappropriate or unwanted physical contact. We recognize that generational, geographical, and cultural norms may influence optimal implementation of these suggestions.

Further research is needed to assess the prevalence of sexual harassment and other behaviors that undermine the safety and success of female mentees in academic pharmacy. This research could inform programs at colleges of pharmacy that seek both to prevent misconduct and to mitigate its impact. At this time, we suggest administrators in colleges and schools of pharmacy should promote a proactive dialogue around this issue with faculty members, preceptors, staff members, and other personnel who supervise students.

\section{ACKNOWLEDGMENT}

The authors wish to thank Ms. Sarah Ashlock for providing editorial support.

\section{REFERENCES}

1. Academic Pharmacy's Vital Statistics. AACP Website. https:// www.aacp.org/article/academic-pharmacys-vital-statistics. Accessed June 5, 2019.

2. Black MC, Basile KC, Breiding MJ, et al. The National Intimate Partner and Sexual Violence Survey: 2010 Summary Report. CDC Website. http://www.cdc.gov/ViolencePrevention/pdf/ NISVS_Report2010-a.pdf. Published November 2011. Accessed June 5, 2019.

3. Gross AM, Winslett A, Roberts M, Gohm CL. An examination of sexual violence against college women. Violence Against Women. 2006;12(3):288-300.

4. Kearl H. The Facts Behind the \#MeToo Movement: A National Study on Sexual Harassment and Assault. Stop Street Harassment; 2018. http://www.stopstreetharassment.org/wp-content/uploads/ 2018/01/Full-Report-2018-National-Study-on-Sexual-Harassmentand-Assault.pdf. Accessed June 5, 2019.

5. What women are up against at work: key findings. LeanIn website. https://leanin.org/sexual-harassment-backlash-survey-results\#keyfinding-1. Accessed June 5, 2019. 


\section{American Journal of Pharmaceutical Education 2019; 83 (10) Article 7533.}

6. Profile of Pharmacy Faculty, 2017-18. AACP Website. https:// www.aacp.org/system/files/PPF_1718-final.pdf. Published February 2018. Accessed June 5, 2019.

7. Lisak D, Gardinier L, Nicksa SC, Cote AM. False allegations of sexual assault: an analysis of ten years of reported cases. Violence Against Women. 2010;16(12):1318-1334. doi:10.1177/ 1077801210387747

8. Zemke R, Raines C, Filipczak B. The Millennials: Be Careful What You Ask For; and, A Field Guide to Mentoring Millennials. In: Generations at Work: Managing the Clash of Boomers, Gen Xers, and Gen Yers in the Workplace. New York, NY: AMACOM, American Management Association; 2013.

9. Piper LE. Generation $Y$ in healthcare: leading millennials in an era of reform. Frontiers of Health Services Management. 2012;29(1):16-28. doi:10.1097/01974520-201207000-00003

10. Shaw ME, Fulton J. Skills for Mentorship. In: Mentorship in Healthcare. Keswick, Cumbria: M \& K Publishing; 2015. http:// eds.b.ebscohost.com.ezproxy2.library.arizona.edu/ehost/ ebookviewer/ebook?sid=1ce976d1-382c-4099-a781fa15a00ed4a4@sessionmgr102\&vid=0\&format=EB.

11. Lease SH. Assertive behavior: a double-edged sword for women at work? Clin Psychol Sci Pract. 2018;25:e12226.

12. Bechard M, Arget M, Lerner J, et al. 2018 RDOC National

Resident Survey. https://residentdoctors.ca/wp-content/uploads/2018/ 10/National-Resident-Survey-2018-R8.pdf.
13. Bronner G, Peretz C, Ehrenfeld M. Sexual harassment of nurses and nursing students. J Advanced Nursing. 2003;42(6):637-644. doi:10.1046/j.1365-2648.2003.02667.x

14. Pennington A, Darby M, Bauman D, et al. Sexual harassment in dentistry: experiences of Virginia dental hygienists. J Dental Hygiene. 2000;74(4):288-295. http://link.galegroup.com.ezproxy2.library.arizona. edu/apps/doc/A69291264/AONE?u=uarizona_main\&sid=AONE\&xid= e7841d05.

15. Douglas KM, Sutton RM. "A Giant Leap for Mankind” but what about women? the role of system-justifying ideologies in predicting attitudes toward sexist language. J Language and Social Psychology. 2014;33(6):667-680. doi:10.1177/0261927x14538638

16. Fischbach A, Lichtenthaler PW, Horstmann N. Leadership and gender stereotyping of emotions. J Personnel Psychology. 2015;14(3):153-162. doi:10.1027/1866-5888/a000136

17. Barnett JE. Mentoring, boundaries, and multiple relationships: opportunities and challenges. Mentoring \& Tutoring: Partnership in Learning. 2008;16(1):3-16. doi:10.1080/13611260701800900

18. Guizzo F, Cadinu M. Effects of objectifying gaze on female cognitive performance: the role of flow experience and internalization of beauty ideals. British J Social Psychology. 2016;56(2):281-292. doi:10.1111/bjso.12170

19. Fredrickson BL, Roberts T-A. Objectification theory: toward understanding women's lived experiences and mental health risks. Psychology of Women Quarterly. 1997;21(2):173-206. doi:10.1111/ j.1471-6402.1997.tb00108.x 